\title{
A MULHER, O MERCADO DE TRABALHO E O PRINCÍPIO DA IGUALDADE
}

WOMEN, THE LABOR MARKET AND THE PRINCIPLE OF EQUALITY

MUJER, MERCADO DE TRABAJO Y PRINCIPIO DE IGUALDAD

Ana Maria Dinardi Barbosa Barros https://orcid.org/0000-0001-8738-2731

Título: Doutoranda Universidad del Museo Social Argentino - UMSA

Buenos Aires - Ar

e-mail: annadinardi@hotmail.com 


\section{RESUMO}

Este trabalho visa mostrar a participação da mulher no mercado de trabalho, além de trazer o nome de algumas mulheres que se destacaram pela luta constante em defesa de seus direitos. Para tanto, foram apresentados dados estatísticos apresentados pelo IBGE e o princípio da igualdade consagrado pela Constituição Federal de 1988, além de dar destaque ao nome de algumas personalidades importantes nessa temática.. A metodologia usada foi a pesquisa bibliográfica. A luta por se estabelecer ainda é muito grande, mas já conseguimos perceber uma pequena melhora em termos da participação em cargos de chefia, um acréscimo, ainda pequeno, das mulheres na política.

Palavras-Chave: Mulheres. Participação na política. Cargos de chefia. Identidade de gênero.

\section{ABSTRACT}

This work aims to show the participation of women in the labor market, in addition to bringing the names of some women who stood out for their constant struggle in defense of their rights. For this purpose, statistical data presented by IBGE and the principle of equality enshrined in the Federal Constitution of 1988 were presented, in addition to highlighting the names of some important personalities in this theme. The methodology used was bibliographic research. The struggle to establish itself is still very great, but we have already noticed a small improvement in terms of participation in leadership positions, an increase, still small, of women in politics.

Keywords: Women. Participation in politics. Management positions. Gender identity

\section{RESUMEN}

Este trabajo tiene como objetivo mostrar la participación de las mujeres en el mercado laboral, además de traer los nombres de algunas mujeres que se destacaron por su constante lucha en defensa de sus derechos. Para ello, se presentaron los datos estadísticos presentados por el IBGE y el principio de igualdad establecido por la Constitución Federal de 1988, además de destacar los nombres de algunas personalidades importantes en este tema La metodología utilizada fue la investigación bibliográfica. La lucha por establecerse es todavía muy grande, pero ya hemos podido ver una pequeña mejora en términos de participación en puestos de liderazgo, un aumento, aún pequeño, de mujeres en la política.

Palabras clave: Mujeres. Participación en política. Posiciones administrativas. Identidad de género.

\section{INTRODUÇÃO}

Perante a lei, homens e mulheres são iguais. Possuem os mesmos direitos e deveres, além da mesma dignidade. Na prática, porém, isso não acontece dessa maneira.

Pensando nessa desigualdade é que surge o interesse para discutir sobre o tema a mulher, o mercado de trabalho e o princípio da igualdade. 
O trabalho se desenvolve em três seções, onde abordamos sobre a Constituição Federal, em seu artigo $5^{\circ}$, trazendo algumas considerações sobre o princípio da igualdade.

Logo em seguida, apresentamos algumas estatísticas sobre o trabalho da mulher, estatísticas essas tirados do IBGE.

Sabemos que a luta para se conseguir direitos sempre foi muito grande. A luta pela identidade de gênero não acaba por aqui. Ela é grande e desgastante. Muitas mulheres foram fundamentais pela luta por essa identidade, portanto, como forma de homenageá-las, importante citar algumas delas.

Por fim, destacamos a importância do princípio pelo empoderamento das mulheres, princípio esse que ajuda o setor privado a se concentrar nos elementos-chave para promover a igualdade entre homens e mulheres no local de trabalho, no mercado e na comunidade.

A defesa dos direitos das mulheres e da igualdade de gênero é um esforço coletivo e contínuo.

\section{A MULHER, O MERCADO DE TRABALHO E O PRINCÍPIO DA IGUALDADE}

A Constituição Federal de 1988, em seu artigo 5, nos informa que "todos são iguais perante a lei, sem distinção de qualquer natureza, garantindo-se aos brasileiros e aos estrangeiros residentes no País a inviolabilidade do direito à vida, à liberdade, à igualdade, à segurança e à propriedade." Traz no inciso I, "homens e mulheres são iguais em direitos e obrigações, nos termos desta Constituição.” (BRASiL, 1988)

O princípio da igualdade prevê a igualdade de aptidões e de possibilidades dos cidadãos de ter tratamento igual, isonômico pela lei. Por esse princípio são vedadas as diferenciações arbitrárias e absurdas, não justificáveis pelos valores da Constituição Federal, e tem por finalidade limitar o poder de quem legisla, interpreta e julga.

$\mathrm{O}$ princípio da igualdade se fundamenta no sentido de que todos os que vivem em sociedade possuem a mesma natureza e dignidade humana. A partir disso se afasta qualquer forma de discriminação que ofenda esse princípio como por exemplo, a negação de igualdade entre o patrão e o empregado.

A igualdade no direito moderno, além de ser um princípio informador de todo o sistema jurídico, reveste-se também da condição de autêntico direito subjetivo. Assim, o cidadão possui o direito indisponível de não ser diferenciado por outros particulares nas mesmas situações em que a lei também não poderia diferençar. (SIQUEIRA JUNIOR, 2020) 
A importância do princípio da igualdade é inquestionável. Essa importância é trazida pela Constituição Federal de 1998, que inaugura o capítulo dos direitos individuais com esse princípio. Isso é reforçado em outras normas constitucionais e infraconstitucionais, e ainda busca a isonomia dos desiguais pela chancela de direitos sociais.

Pela lei, homens e mulheres são iguais. Possuem os mesmos direitos e deveres, além da mesma dignidade. Sim, mas existem as diferenças físicas, hormonais, emocionais e psicológicas.

Diferenças essas, naturais e saudáveis. Porém, há os que usam essas diferenças para se sentir superior ou inferior ao próximo. Mulheres são desvalorizadas por essa suposta "superioridade masculina". Em pleno século XXI, mulheres são preteridas diversos espaços da sociedade.

No mercado de trabalho, ainda que a diferença salarial entre homens e mulheres tenha diminuído, as mulheres ganham 20,5\% a menos que os homens, segundo o IBGE, através da Pesquisa Nacional por Amostra de Domicílios Contínua (PNAD Contínua).

No quadro abaixo podemos verificar a situação da mulher no mercado de trabalho no período de 2012 a 2018.

Quadro 1 - Mulher no Mercado de Trabalho - 2012/2018

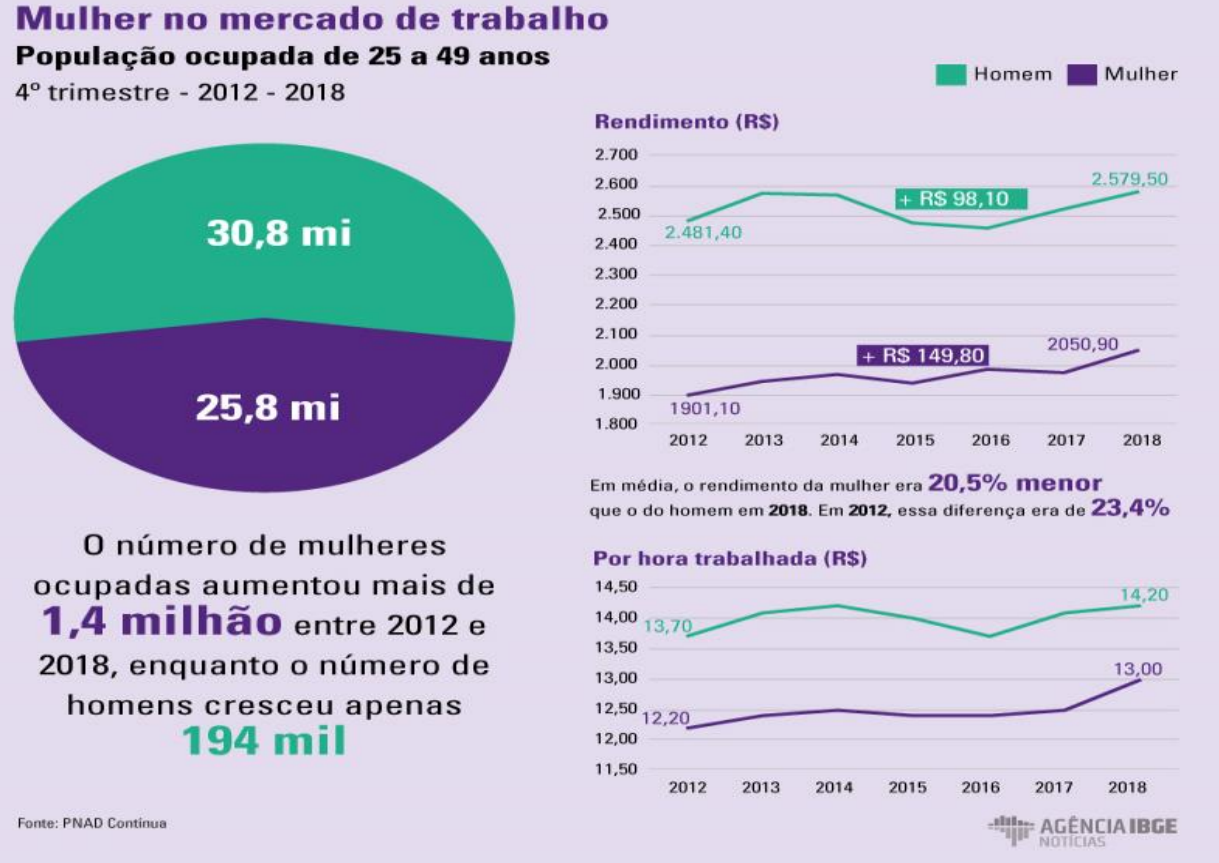

Fonte: IBGE. Censo Agro. Disponível em: https://censos.ibge.gov.br/agro/2017/2012-agencia-denoticias/noticias/23924-diferenca-cai-em-sete-anos-mas-mulheres-ainda-ganham-20-5-menos-quehomens.html. Acesso em: 03 mar. 2021. 
Apontado na pesquisa os dados que mostram que as mulheres trabalham, em média, três horas por semana a mais do que os homens, combinando trabalhos remunerados, afazeres domésticos e cuidados de pessoas. Mesmo assim, e ainda contando com um nível educacional mais alto, elas ganham, em média, 76,5\% do rendimento dos homens. (IBGE, 2019). Portanto, trabalham mais, estudam mais e ganham menos.

\begin{abstract}
Vários fatores contribuem para as diferenças entre homens e mulheres no mercado de trabalho. Por exemplo, em 2016, as mulheres dedicavam, em média, 18 horas semanais a cuidados de pessoas ou afazeres domésticos, $73 \%$ a mais do que os homens (10,5 horas). Essa diferença chegava a $80 \%$ no Nordeste (19 contra 10,5). Isso explica, em parte, a proporção de mulheres ocupadas em trabalhos por tempo parcial, de até 30 horas semanais, ser o dobro da de homens $(28,2 \%$ das mulheres ocupadas, contra $14,1 \%$ dos homens).

"Em função da carga de afazeres e cuidados, muitas mulheres se sentem compelidas a buscar ocupações que precisam de uma jornada de trabalho mais flexível", explica a coordenadora de População e Indicadores Sociais do IBGE, Barbara Cobo, complementando que "mesmo com trabalhos em tempo parcial, a mulher ainda trabalha mais. Combinando-se as horas de trabalhos remunerados com as de cuidados e afazeres, a mulher trabalha, em média, 54,4 horas semanais, contra 51,4 dos homens." (IBGE, 2019)
\end{abstract}

Gráfico 1 - Rendimento médio de salário e a diferença entre mulheres e homens.

\title{
Rendimento habitual médio mensal de todos os trabalhos e razão de rendimentos, por sexo
}

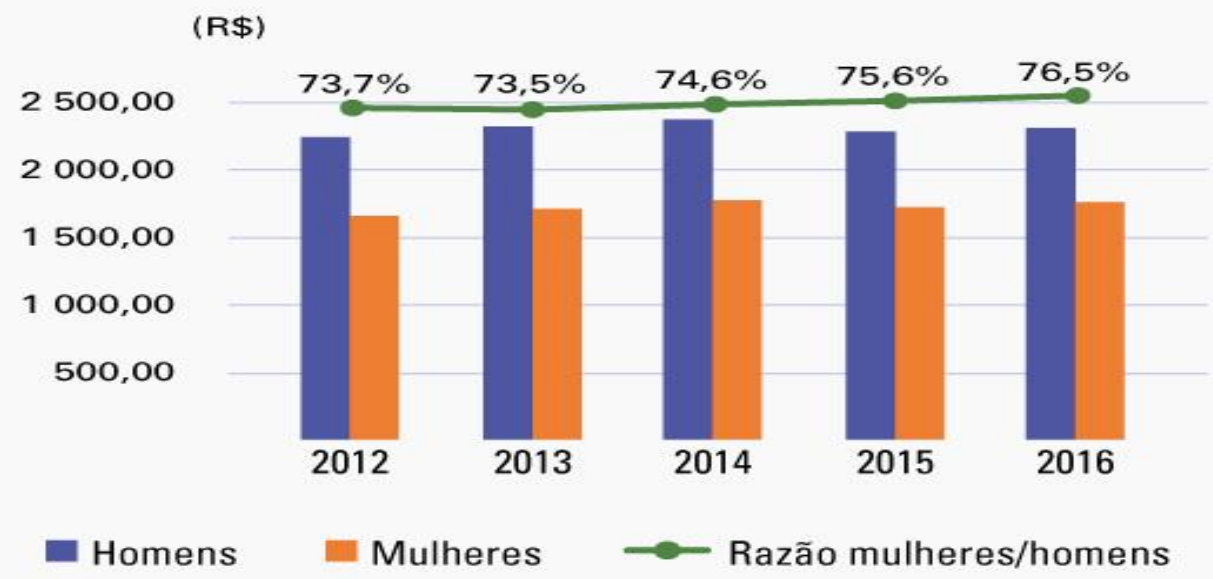

Fonte: IBGE, Pesquisa Nacional por Amostra de Domicílios Contínua 2012-2016.

Fonte: IBGE. INSTITUTO BRASILEIRO DE GEOGRAFIA E ESTATÍSTICA. IBGE. PNAD Contínua. Mulher estuda mais, trabalha mais e ganha menos do que o homem. Disponível em: 
https://agenciadenoticias.ibge.gov.br/agencia-noticias/2012-agencia-de-noticias/noticias/20234mulher-estuda-mais-trabalha-mais-e-ganha-menos-do-que-o-homem. Acesso em: 01 mar. 2021.

Mesmo que trabalhem mais e estudem mais as mulheres seguem ganhando menos. Apesar da diferença entre os rendimentos de homens e mulheres ter diminuído nos últimos anos, em 2019 elas ainda recebiam o equivalente a 77,7\% dos rendimentos dos homens.

\begin{abstract}
A dificuldade em ascender a postos de gestão também é outro desafio que ainda não foi superado, mas os estudos apontam que a participação delas nessas áreas vem crescendo. Dos 2,6 milhões de empregos em cargos de chefia registrados na Relação Anual de Informações Sociais (Rais) em 2017, as mulheres somavam 1.143.821 vínculos empregatícios, 43,8\% do total. (KREUS, 2020)
\end{abstract}

No ambiente de trabalho, a mulher, que já enfrenta inúmeros desafios, também está sujeita a duas formas de violência, nem sempre perceptíveis: o assédio moral e sexual. Sobre este último, o artigo 216 A do Código Penal define o crime de assédio sexual como "constranger alguém com o intuito de obter vantagem ou favorecimento sexual, prevalecendo-se o agente da sua condição de superior hierárquico ou ascendência inerentes ao exercício de emprego, cargo ou função. A pena, neste caso, é de detenção de um a dois anos.

Em estudo realizado pelo Instituto Patrícia Galvão, Percepções sobre violência e assédio contra mulheres no trabalho, mostra que $40 \%$ das entrevistadas já foram insultadas ou já ouviram gritos no trabalho, contra $13 \%$ dos homens.

Entre os trabalhadores que tiveram seu trabalho excessivamente supervisionado, $40 \%$ também são mulheres e $16 \%$ são homens.

A pesquisa ainda indica que, para $92 \%$ dos entrevistados, as mulheres sofrem mais situações de constrangimento e assédio no ambiente de trabalho do que os homens. (LIMA, 2021)

A pesquisa mostra que $39 \%$ das mulheres receberam de pessoas do sexo oposto convites para sair ou insinuações constrangedoras, contra $9 \%$ dos homens que receberam convites na mesma situação; 125 de mulheres já sofreram agressões sexuais (estupro) contra 1\% dos homens. Foram relatados, ainda, que 36\% das mulheres disseram ter sofrido preconceito ou abuso no trabalho, pelo simples fato de serem mulheres, contra 15\% dos homens. (LIMA, 2021)

São muitos os preconceitos, são muitas as violências sofridas pelas mulheres pelo simples fato de serem mulheres.

Outro ponto que nos causa perplexidade é que em pleno século XXI, mulheres que são mães ainda enfrentam dificuldade para manter seus empregos ou para conseguir se recolocar. 
BASTOS, A. M. D. A mulher, o mercado de trabalho e o princípio da igualdade.

R. Científica UBM - Barra Mansa (RJ), ano XXVI, v. 23, n. 45, 2 . Sem. 2021 p. 52-63. ISSN 1516-4071

O preconceito do mercado com a maternidade também reflete nos salários. Comparações feitas pelo Idados, com base na Pesquisa Nacional por Amostra de Domicílios Contínua do segundo trimestre de 2018, mostram que mulheres com filhos recebem salário mensal, em média, $\mathrm{R} \$ 554,88$ menor do que as sem filhos. A discrepância é ainda maior quando a família cresce: mulheres com três filhos recebem 66\% a menos que aquelas que não os têm. (PLATAFORMA ..., 2019)

Pesquisas mostram que a tão sonhada igualdade, defendida pelas nações que adotam o Estado Democrático de Direito, não existe na prática. O que se observa é a luta incansável de mulheres para conquistarem seus espaços na sociedade.

Defender os direitos das mulheres é uma missão. Várias são as mulheres que se destacam nessa luta. $\mathrm{O}$ feminismo não é contrário de machismo. $\mathrm{O}$ machismo é a dominação do homem sobre a mulher; enquanto o feminismo é a busca por equidade de gêneros. Além do mais, não é preciso se autodenominar feminista para praticar o feminismo, nem ser ativista para ser feminista. Basta querer conquistar direitos.

O feminismo já conquistou muitos direitos para as mulheres, mas ainda luta por tantos outros. Algumas mulheres quebram tabus e servem como inspiração para todas nós. Muitas mulheres merecem destaque, aqui citamos algumas dentre outras tantas. Em nossas pesquisas encontramos um trabalho de Babi Nascimento, de março de 2020, no qual destaca 20 mulheres, aqui algumas das citadas por ela.

\begin{abstract}
Alicia Keys
A cantora nova-iorquina Alicia Keys manifestou-se contra o costume social que diz que as mulheres devem estar sempre perfeitas atrás de artifícios, como maquiagens. "Não quero me esconder mais", escreveu a cantora em uma carta publicada na revista feminista Lenny Letter ao explicar por que estava deixando de usar maquiagem. (NASCIMENTO, 2020)

Djamila Ribeiro
\end{abstract}

Mestre em Filosofia Política e uma das principais referências do movimento feminista negro atual, Djamila Ribeiro é membro da Simone de Beauvoir Society, conferencista internacional e foi secretária adjunta da Secretaria de Direitos Humanos e Cidadania de São Paulo na administração de Fernando Haddad. Foi intitulada como "a voz da consciência negra feminina no Brasil”" pela Vice. (NASCIMENTO, 2020)

Ellen Page

Nossa querida Hermione, de Harry Potter, é Embaixadora da Boa Vontade da ONU Mulheres e do movimento HeForShe. Em 2014, seu discurso emocionado na ONU sobre igualdade política, econômica e social entre homens e mulheres a colocou como referência atual do gênero. Ela também promoveu uma iniciativa que consistia em deixar livros de conteúdo feminista pelo metrô de Londres, para conscientizar a população. (NASCIMENTO, 2020)

Elza Soares 
BASTOS, A. M. D. A mulher, o mercado de trabalho e o princípio da igualdade.

R. Científica UBM - Barra Mansa (RJ), ano XXVI, v. 23, n. 45, 2 . Sem. 2021 p. 52-63. ISSN 1516-4071

Elza passou fome na infância, perdeu maridos, filhos, mãe, sofreu com a falta de dinheiro e ainda enfrentou o julgamento do Brasil inteiro por se relacionar com Garrincha. "Eu acho que a mulher do fim do mundo é aquela que busca, é aquela que grita, que reivindica, que sempre fica de pé. No fim, eu sou essa mulher", disse Elza Soares em entrevista ao HuffPost Brasil.

Eleita como a cantora brasileira do milênio pela Rádio BBC de Londres, Elza venceu o Grammy Latino com o álbum "A Mulher do Fim do Mundo". O disco fala sobre empoderamento feminino, racismo e violência doméstica, entre outros temas. (NASCIMENTO, 2020)

\section{Frida Kahlo}

Apesar de ter falecido há mais de 50 anos, a obra de Frida Kahlo segue presente como um motor da arte contemporânea. Suas pinturas são expressões do seu eu mais profundo. $\mathrm{O}$ buço, as axilas e as sobrancelhas não depiladas eram uma maneira de atentar contra as imposições sociais. (NASCIMENTO, 2020)

\section{Hillary Clinton}

Em 1995, Hillary Clinton surpreendeu o mundo com o discurso "Direitos das Mulheres são Direitos Humanos", no qual as mulheres e os seus direitos ostentam seus papéis de destaque. Embora ela não tenha conseguido se tornar a primeira presidenta dos Estados Unidos, sua missão foi louvável e serviu como exemplo para milhões de mulheres. (NASCIMENTO, 2020)

\section{Marielle Franco}

Marielle Franco, assassinada em 2018 em um atentado, foi Vereadora da Câmara do Rio de Janeiro e também Presidente da Comissão da Mulher da Câmara. Nascida e criada na favela da Maré, Mariele dizia que ocupar a política é fundamental para reduzir as desigualdades que nos cercam. (NASCIMENTO, 2020)

\section{Laudelina de Campos Melo}

A mineira Laudelina de Campos Melo foi a fundadora do primeiro sindicato de trabalhadoras domésticas do Brasil. A atuação dela foi fundamental para a categoria conquistar o direito à Carteira de Trabalho e à Previdência Social. (NASCIMENTO, 2020)

\section{Maria da Penha}

Uma das mulheres mais importantes da história atual do Brasil. Maria da Penha Maia Fernandes é líder de movimentos de defesa dos direitos das mulheres e vítima de violência doméstica. Ela perdeu os movimentos do corpo ao levar um tiro do marido enquanto dormia e seu nome virou Lei em 2006, estipulando aumento das punições às agressões contra a mulher, além de estabelecer medidas para proteger a integridade física e psicológica de mulheres vítimas de violência. (NASCIMENTO, 2020)

\section{Lina Bo Bardi}

Achillina Bo, mais conhecida como Lina Bo Bardi, foi uma arquiteta modernista ítalobrasileira, uma das figuras mais importantes na arquitetura Latino-americana. É conhecida por ter projetado um dos cartões postais mais conhecidos da cidade de São Paulo, o MASP (Museu de Arte de São Paulo), inaugurado em 1968. Além disso, também é possível ver o resultado do seu talento em edifícios como o SESC Pompeia e o Teatro Oficina, ambos em São Paulo. (NASCIMENTO, 2020) 
BASTOS, A. M. D. A mulher, o mercado de trabalho e o princípio da igualdade.

R. Científica UBM - Barra Mansa (RJ), ano XXVI, v. 23, n. 45, 2 . Sem. 2021 p. 52-63. ISSN 1516-4071

Michelle Obama

Um exemplo em tudo, a ex-primeira dama defendeu os direitos das mulheres antes e durante sua passagem pela Casa Branca, aproveitando sua enorme influência. Michelle Obama é a precursora do Estado da Mulher, uma campanha que trata dos direitos da mulher e de questões como injustiça de trabalho e da violência de gênero. Meryl Streep, Oprah Winfrey e Kerry Washington também fizeram parte dessa iniciativa. (NASCIMENTO, 2020)

Patricia Arquette

Foi uma das primeiras atrizes que reivindicam salário igual entre homens e mulheres em Hollywood, durante o discurso de agradecimento no Oscar 2015. Jennifer Lawrence, Jessica Chastain, Charlize Theron, Meryl Streep e Amanda Seyfried juntaram-se a ela. (NASCIMENTO, 2020)

PAGU - Patrícia Rehder Galvão

Pagu foi escritora, poeta, diretora de teatro, tradutora, desenhista e jornalista. Ela militou para o Partido Comunista e foi a primeira mulher presa no Brasil por motivações políticas, após participar da organização de uma greve de estivadores em Santos. Ao longo da vida, foi presa 23 vezes por causa de sua militância transgressora. Em suas obras, defendeu a mulher pobre e criticou o papel conservador feminino na sociedade. (NASCIMENTO, 2020)

Pitty

A cantora baiana Pitty luta por direitos iguais entre gêneros. Em entrevistas, afirmou que acredita que o debate sobre feminismo é necessário e saudável, principalmente para esclarecer informações desencontradas e preconceitos contra o movimento.

"O feminismo não é só bom para as mulheres, para os homens também, para a sociedade, pois se trata de igualdade, não de supremacia. O machismo oprime os homens também. Acho que no dia que eles perceberem isso, vai ser uma grande revolução", disse a baiana. (NASCIMENTO, 2020)

\section{$\underline{\text { Shonda Rhimes }}$}

Roteirista de séries como Grey's Anatomy e Scandal, e produtora de How To Get Away With Murder, Shonda Rhimes evidencia mulheres fortes e determinadas em suas obras. "As coisas estarão melhores quando deixarmos de fazer essas perguntas. Quando não nos perguntarmos se está melhor a presença de mulheres na televisão ou quantas mulheres trabalham no meio", afirmou Shonda. (NASCIMENTO, 2020)

\section{Ellen DeGeneres}

Ellen DeGeneres é uma das apresentadoras mais importantes nos Estados Unidos (e do mundo) a frente do programa The Ellen DeGeneres Show e utiliza esse espaço para falar sobre questões humanitárias. A americana luta por temas como igualdade de gênero, direitos LGTB, questões raciais, contra o bullying e o aquecimento global. Em 2016, Barack Obama concedeu a ela a Medalha da Liberdade reconhecendo todo o seu trabalho filantrópico. (NASCIMENTO, 2020)

Viola Davis

A atriz Viola Davis foi a primeira mulher negra a ganhar o Emmy de melhor atriz. O discurso dela na ocasião repercute até hoje. Uma das partes mais marcantes é: “A 
BASTOS, A. M. D. A mulher, o mercado de trabalho e o princípio da igualdade.

R. Científica UBM - Barra Mansa (RJ), ano XXVI, v. 23, n. 45, 2 . Sem. 2021 p. 52-63. ISSN 1516-4071

única coisa que separa as mulheres negras de qualquer outra pessoa é a oportunidade. Você não pode ganhar um Emmy por papéis que simplesmente não existem". Viola é sinônimo de representatividade. (NASCIMENTO, 2020)

Yoko Ono

A carreira da inimitável Yoko Ono foi marcada pela faceta reivindicativa e excêntrica. "Toda mulher tem medo de se dizer feminista por causa das possíveis reações, mas o aspecto agradável disso é que torna possível uma melhor compreensão sobre a feminilidade", disse a compositora e artista plástica ao The Washington Post. (NASCIMENTO, 2020)

A desigualdade e a necessidade de lutarmos por direitos só serão transformados quando mudarmos a mentalidade do povo de maneira geral. O primeiro passo é fazer valer, na prática, o princípio da igualdade. Mulheres precisam ter as mesmas oportunidades que os homens têm. A mudança deverá ocorrer nas escolas, onde meninos e meninas se engajem em projetos e pesquisas com isonomia, com igualdade de condições. Só a educação poderá fazer frente a tudo isso.

Os meninos precisam ser educados sabendo respeitar as mulheres. É necessário entenderem que mulheres não são objetos de desejos. É preciso mostrar o que é respeito, empatia e consentimento para que vejam as mulheres como pessoas que têm os mesmos direitos e deveres que eles.

Por outro lado, é importante empoderar as mulheres para que participem integralmente de todos os setores da economia e em todos os níveis de atividade econômica, pois isso é essencial para que possam:

Construir economias fortes; Estabelecer sociedades mais estáveis e justas; Atingir os objetivos de desenvolvimento, sustentabilidade e direitos humanos internacionalmente reconhecidos; Melhorar a qualidade de vida para as mulheres, homens, famílias e comunidades e Impulsionar as operações e as metas dos negócios. (ONU MULHERES, 2017)

Na cartilha Princípios de Empoderamento das Mulheres, elaborada pela ONU Mulheres, vimos que vários são os estudos que corroboram com os itens acima citados, alguns deles:

- O poder da paridade: Como fazer avançar a igualdade de gênero pode adicionar US\$ 12 trilhões ao crescimento mundial, da Mckinsey \& Co;

- O Progresso das Mulheres no Mundo 2015-2016 - Transformar as economias para realizar direitos - , da ONU Mulheres;

- Mulheres em Gestão e Negócios: Ganhando Impulso, da Organização Internacional do Trabalho (OIT). 
Para que isso aconteça é necessário a inclusão dos talentos, habilidades, experiências e energia das mulheres em ações afirmativas e políticas públicas. Os Princípios de Empoderamento das Mulheres trazem alguns pontos que ajudam o setor privado a se concentrar nos elementos-chave para promover a igualdade entre homens e mulheres no local de trabalho, no mercado e na comunidade.

\begin{abstract}
Assegurar a perspectiva de gênero em políticas e operações existentes, assim como gerar novas políticas e estratégias para a igualdade de gênero, requer técnicas, ferramentas e práticas. O Pacto Global das Nações Unidas (UNGC) e a ONU Mulheres elaboraram, em um processo consultivo internacional que incluiu várias partes interessadas, uma "perspectiva de gênero" por meio da qual os negócios podem investigar e analisar as atuais iniciativas, metas e práticas de elaboração de relatórios. (ONU MULHERES, 2017)
\end{abstract}

Importante para os gestores estimularem o tratamento justo e igualitário entre homens e mulheres no ambiente de trabalho, respeitando as diferenças e apoiando a não discriminação. Muito mais do que lucros, essa atitude promove o respeito.

\title{
3 CONSIDERAÇÔES FINAIS
}

$\mathrm{O}$ acesso aos direitos não surgiu da noite para o dia. Ele foi conquistado com muita dificuldade e aos poucos pelas minorias e, no caso dos direitos das mulheres, os movimentos feministas tiveram grande importância nesse processo.

A igualdade de gênero tem uma pauta histórica dentre as reivindicações sociais e populares no mundo todo. Há muito as mulheres se unem por direitos civis, políticos e sociais, como direito ao voto, ao divórcio, a educação, a igualdade salarial, condições adequadas de trabalho, direitos sexuais e reprodutivos e participação em espaços de poder.

A igualdade de gênero é um projeto em construção. Esse processo já soma diversos movimentos, reivindicações e lutas, nacional e internacionalmente. De lá para cá, por maiores que tenham sido as dificuldades, são muitas as conquistas das mulheres. Cada vez mais as leis e as políticas públicas visam o bem-estar social das pessoas, independentemente de seu gênero e as mulheres vêm ganhando espaço nos campos político e econômico.

Prevista no inciso I do artigo $5^{\circ}$, a igualdade de gênero é uma luta de todos e por todos. Ter esse direito assegurado pela Constituição é de inegável importância, mas a história já mostrou que apenas isso não garante sua eficiência prática. A defesa dos direitos das mulheres e da igualdade de gênero é, portanto, um esforço coletivo e contínuo.

\section{REFERÊNCIAS}


BRASIL. [Constituição (1988). Constituição da República Federativa do Brasil de 1988. Disponível em: http://www.planalto.gov.br/ccivil_03/constituicao/constituicaocompilado.htm. Acesso em: 01 mar. 2021.

IBGE. INSTITUTO BRASILEIRO DE GEOGRAFIA E ESTATÍSTICA. IBGE. PNAD Contínua. Mulher estuda mais, trabalha mais e ganha menos do que o homem.

Disponível em: https://agenciadenoticias.ibge.gov.br/agencia-noticias/2012-agencia-denoticias/noticias/20234-mulher-estuda-mais-trabalha-mais-e-ganha-menos-do-que-o-homem. Acesso em: 01 mar. 2021.

IBGE. Censo Agro. Disponível em: https://censos.ibge.gov.br/agro/2017/2012-agencia-denoticias/noticias/23924-diferenca-cai-em-sete-anos-mas-mulheres-ainda-ganham-20-5menos-que-homens.html. Acesso em: 03 mar. 2021.

KREUS, Mauro. Mulher, mercado de trabalho e o princípio da igualdade. CRA-BA, 06 mar. 2020.Disponível em: https://cra-ba.org.br/mulher-mercado-de-trabalho-e-o-principio-daigualdade/. Acesso em: 01 mar. 2021.

LIMA. Mariana. 40\% das mulheres já foram insultadas no ambiente de trabalho.

Observatório do Terceiro Setor, 05 jan. 2021. Disponível em:

https://observatorio3setor.org.br/noticias/40-das-mulheres-ja-foram-insultadas-no-ambientede-trabalho/. Acesso em: 01 mar. 2021.

NASCIMENTO, Babi. Direitos das mulheres: 20 exemplos de verdadeiras lutadoras! Zankyou, 08 mar. 2020. Disponível em: https://www.zankyou.com.br/p/direitos-dasmulheres-20-exemplos-de-verdadeiras-lutadoras. Acesso em: 01 mar. 2021.

ONU MULHERES. Princípios de empoderamento de mulheres. In: ONU MULHERES. Cartilha ONU Mulheres. Disponível em: https://www.onumulheres.org.br/wpcontent/uploads/2016/04/cartilha_ONU_Mulheres_Nov2017_digital.pdf. Acesso em: 01 mar. 2021.

PLATAFORMA tenta ajudar mães que ainda enfrentam preconceito no mercado de trabalho. UGT, 2019. Disponível em: https://ugt.org.br/post/22831-Plataforma-tenta-ajudar-maes-queainda-enfrentam-preconceito-no-mercado-de-trabalho.

SIQUEIRA JUNIOR, Paulo Hamilton. Princípio da igualdade no processo penal. In: Enciclopédia Jurídica da PUCSP. Disponível em: https://enciclopediajuridica.pucsp.br/verbete/445/edicao-1/principio-da-igualdade-noprocesso-penal. Acesso em: 01 mar. 2021. 